\title{
Number Sense: The Underpinning Understanding for Early Quantitative Literacy
}

Effie Maclellan

University of Strathclyde, e.maclellan@strath.ac.uk

Follow this and additional works at: https://digitalcommons.usf.edu/numeracy

Part of the Pre-Elementary, Early Childhood, Kindergarten Teacher Education Commons, and the Science and Mathematics Education Commons

\section{Recommended Citation}

Maclellan, Effie. "Number Sense: The Underpinning Understanding for Early Quantitative Literacy."

Numeracy 5, Iss. 2 (2012): Article 3. DOI: http://dx.doi.org/10.5038/1936-4660.5.2.3 


\title{
Number Sense: The Underpinning Understanding for Early Quantitative Literacy
}

\begin{abstract}
The fundamental meaning of Quantitative Literacy (QL) as the application of quantitative knowledge or reasoning in new/unfamiliar contexts is problematic because how we acquire knowledge, and transfer it to new situations, is not straightforward. This article argues that in the early development of QL, there is a specific corpus of numerical knowledge which learners need to integrate into their thinking, and to which teachers should attend. The paper is a rebuttal to historically prevalent (and simplistic) views that the terrain of early numerical understanding is little more than simple counting devoid of cognitive complexity. Rather, the knowledge upon which early QL develops comprises interdependent dimensions: Number Knowledge, Counting Skills and Principles, Nonverbal Calculation, Number Combinations and Story Problems - summarised as Number Sense. In order to derive the findings for this manuscript, a realist synthesis of recent Education and Psychology literature was conducted. The findings are of use not only when teaching very young children, but also when teaching learners who are experiencing learning difficulties through the absence of prerequisite numerical knowledge. As well, distilling fundamental quantitative knowledge for teachers to integrate into practice, the review emphasises that improved pedagogy is less a function of literal applications of reported interventions, on the grounds of perceived efficacy elsewhere, but based in refinements of teachers' understandings. Because teachers need to adapt instructional sequences to the actual thinking and learning of learners in their charge, they need knowledge that allows them to develop their own theoretical understanding rather than didactic exhortations.
\end{abstract}

\section{Keywords}

Number sense, Pedagogy, Number knowledge, Counting skills and principles, Nonverbal calculation, Number combinations

\section{Creative Commons License}

cc) (i) (8)

This work is licensed under a Creative Commons Attribution-Noncommercial 4.0 License

\section{Cover Page Footnote}

Effie Maclellan is Research Professor in Education at the University of Strathclyde, Scotland. The overall thrust of her research and scholarship is in Promoting Effective Learning and Assessment. Within this she retains an enduring interest in Pedagogical Knowledge for Mathematics Teaching; Sophisticated/Naive Numerical Competence; Developmental Progression in Numeracy, and Beliefs about Mathematics Teaching. 


\section{Introduction}

Being quantitatively literate means being able to apply, appropriately, quantitative knowledge in authentic contexts (Madison and Steen 2008). Quantitative knowledge may not be all that is required to solve a problem but in recognising that quantitative knowledge may be part of the solution, the user is evidencing QL at least in part. QL is therefore a ubiquitous need (Hughes-Hallett 2001). There is no argument with the proposition that using and interpreting quantitative information is important in today's society. However, the ability to apply quantitative knowledge in new or unfamiliar contexts is problematic. Firstly, in the classroom, learners tend to discount their intuitive knowledge of the world and view mathematics as artificial and disconnected from reality (Greer, Verschaffel, and De Corte 2002). Learners may evidence comprehensive QL in the real world but when presented with a similar mathematical situation in the classroom demonstrate bewildering ignorance (Nunes, Schliemann, and Carraher 1993). Further, because learners initially experience quantitative problems in class as being solvable by algorithmic application of the four basic arithmetic operations, they rarely evaluate the reasonableness or cultural relevance of either the actual problems or their solutions (Verschaffel et al. 2010; Enyedy and Mukhopadhyay 2007). Thus learners may possess relevant knowledge but be unaware of its appropriateness in novel situations. The transfer of quantitative ideas from one situation to a new and different one is a defining characteristic of QL, and supporting this development requires rich domain and pedagogical knowledge (Seymour and Lehrer 2006) and self-regulation (Throndsen 2011).

A second reason for caution about the meaning of 'application' is that all mathematical domain knowledge has to be actively constructed by learners for themselves. There is plenty of evidence that children are active in structuring their own mathematical knowledge. We are also becoming aware of the importance of neural activity in number tasks (De Smedt et al. 2010). It is within the powers of us all (excepting the neurologically disabled) to shape the anatomy and physiology of our brains. Through active involvement in experiences we sculpt the way that our brains work to change neurons, synapses, and brain activity. Recent studies show that quantification tasks such as representing numbers and activating addition, subtraction, multiplication and division originate in different parts of the brain. For these to be used in numerical operations and problemsolving, new neural pathways have to be formed, requiring learners to coordinate multiple brain structures (Piazza 2010). Particularly in the early stages of new learning, neural coordination is demanding (De Smedt and Verschaffel 2010), requiring customised, stage-appropriate practice to establish a pathway securely 
(Obersteiner et al. 2010). Learners' mindful and effortful engagements in knowledge acquisition and metacognitive monitoring (De Corte 2010) are therefore of fundamental importance. So teaching has to accommodate learners' thinking in order to promote QL.

Pedagogical accommodation of learners' thinking necessitates teachers' reflection on practice (Nathan, Eilam, and Kim 2007; Sfard 2007). Several factors problematise such reflection. Capacity for quantitative reasoning requires relevant and necessary knowledge (Kuhn and Pearsall 2000). Without cognitive content (knowledge and information) one cannot reason (Marzano and Kendall 2007). However, the nature and type of quantitative knowledge that teachers possess is a contested issue (Murray 2007), underpinning the irony of Madison's (2001) claim that QL is everybody's orphan. Many teachers have a limited understanding of how children learn number and neither appreciate the foundational importance of sound underpinning knowledge nor what they can do to support its development (Chard et al. 2008; Levenson, Tsamir, and Tirosh 2010; Yackel, Underwood, and Elias 2007; Kühne, Van Den Heuvel-Panhuizen, and Ensor 2005; Clements and Samara 2007). Further, there is confusion in what learners do with the quantitative knowledge they have. Many numerical difficulties experienced by learners are rooted in poorly developed underpinning knowledge (Chard et al. 2008; Jordan et al. 2007; Lembke and Foegen 2009; Mazzocco and Thompson 2005; Baroody, Bajwa, and Eiland 2009). Gaps in underpinning knowledge are often not detected until well into school when children are expected to draw on mature additive reasoning and the more sophisticated multiplicative reasoning (Biddlecomb and Carr 2011; Butler, Beckingham, and Lauscher 2005; Desoete and Grégoire 2006; Behr et al. 1994). This article seeks to determine the underpinning knowledge needed to support early QL and argues for the importance of all mainstream teachers being aware of such knowledge to make nuanced judgements as to what support any one child needs to develop QL.

\section{Methodology}

The method adopted was that of Realist Synthesis (Pawson et al. 2004), a derivative of systematic review technology (Newman and Dickson 2012). It seeks to explain the complexity of some social phenomenon rather than strive for completeness or comprehensiveness. The aim was to determine necessary numerical knowledge to support the emergence of QL. The identification of literature domains to be sampled evolved through increased understanding of the study's aim, with an informal search of current and recent psychology and education domains suggesting that relevant evidence would be available therein. Purposive sampling of the literatures, while problematic in quantitative studies 
(Newby 2010), was consistent with a qualitative approach (Palys 2008). Literature searching continued until theoretical saturation in any one dimension had been reached and no significant new findings were emerging. The technique of snowballing (pursuing references to companion pieces that had explored the same ideas through citation-tracking in databases) was the principal search strategy (Greenhalgh et al. 2004). Studies were selected if they met the accountability criteria of relevance and rigour (Pawson et al. 2004): relevance being satisfied if the study's content(s) contributed to addressing the research aim and rigour being satisfied through using only peer-reviewed publications. The aim of the review is to inform pedagogical thinking. As well as distilling fundamental quantitative knowledge for teachers to integrate into practice, the review suggests that improved pedagogy is less a function of literal applications of reported interventions, on the grounds of perceived efficacy elsewhere, but based in refinements of teachers' understandings. Because teachers need to adapt instructional sequences to the actual thinking and learning of learners in their charge, they need knowledge that allows them to develop their own theoretical understanding rather than didactic exhortations (Gravemeijer 2004; Sarama and Clements 2004).

\section{Number Sense - The Essential Meaning of Early QL}

Number Sense, in Education, is general understanding of Number Knowledge and Numeration Processes (Jordan, Glutting, and Ramineni 2008; Malofeeva et al. 2004; Berch 2005) together with the facility to use/invent flexible and efficient strategies for handling problems using both natural and rational number (Behr et al. 1994).

Number Knowledge is an understanding of quantity involving zero, fractional and whole units which allows us to express quantitative relationships (Davydov 1982). Numbers are used as measures of quantities: 'there are 12 children in the class', '2 children went out to play'. Numbers are not the same as quantities because we can conceptualise large and small quantities without any measurement as in 'the shopping centre was very busy with shoppers' or 'there were hardly any lorries on the road in the icy weather'. Numbers also express relationships between quantities as in 'there are 2 more boys than girls in my class'. The relationships between quantities are more important than the quantities themselves because relationships reflect numerical complexity (Thompson 1993). For example, what is commonly known as a Change Problem: 'Joe has 8 marbles and Tom gives him 5 more so how many marbles does Joe have now' is about determining quantity, as is what is commonly known as a Combine Problem: 'Joe has 8 marbles and Tom has 5 marbles. How many marbles do they have altogether'. But 'Joe has 8 marbles. Tom has 5 marbles. How many more marbles 
does Joe have' is a Compare Problem, which is about determining the relationship between the quantities and is much more difficult for children (Riley, Greeno, and Heller 1983). The correct answer, 3, refers neither to Joe's marbles nor Tom's marbles: it refers to the relation (the difference) between the numbers of marbles each boy has. Children may experience difficulty with the relational dimension of number if they only experience counting in a cardinal context, without adequate consideration of its ordinal context. However, for people to develop the 'habit of mind' to identify numerical structures (Hughes-Hallett 2001) they need to construct relationships between quantities (Nunes and Bryant 2009; Davydov 1982; Thompson 1993), because a grasp of the part-whole relationship (which counting facilitates) is critical to the development of quantitative reasoning (Olive and Çağlayan 2008).

Numeration is commonly understood as counting. More prosaically, it is the process of specifying each member of a sequence in some systematic order. Numeration may be fashioned incrementally, decrementally, or in some pattern (counting forwards, backwards, in 'two' or in 'tens, say). Klein and Starkey (1987) distinguish between three enumerative processes: numerosity perception, correspondence construction, and counting. Numerosity perception, otherwise known as 'subitising', is the perceptual apprehension of a small collection of objects ( 2 or 3 ). Debates continue about the criterial elements of subitising and about its relationship with quantification overall. Subitising appears to precede and support the development of counting (Sarama and Clements 2009; Le Corre et al. 2006) but, as its pedagogical implications are very hazy, it is beyond the scope of this article to give differentiated consideration to the idea. Correspondence construction (otherwise known as one-to-one correspondence) is the psychological mapping of every member of a collection of objects onto one and only one member of another collection of objects, and is therefore a necessary precursor to counting. For example, planning the seating arrangement for a formal dinner party would involve correspondence construction. The third enumerative process, counting, involves correspondence construction to pair a unique number with each object in the collection. Numeration processes and the manipulations that they spawn have to be well linked to Number Knowledge for QL to develop. It is this "propensity and ability to use numbers and quantitative methods as a means of communicating, processing and interpreting information" (McIntosh, Reys, and Reys 1992) (p.4) which constitutes Number Sense.

The characterisation of Number Sense offered here implies that learners are better not taught computational techniques (such as how to add or subtract multidigit numbers, or an acronym chant for long division) as these reduce to algorithms the heuristic value of different strategies. Rather, meaningful use of numerical information within an authentic context is the essence of Number Sense and must therefore be a significant consideration in the teacher's practice. 


\section{Necessary Knowledge for teaching early QL}

The central importance of Number Sense suggests that its constituent elements are important considerations for teachers, not as a set of learning outcomes to be evidenced or as a technology of procedures to be pursued, but as pedagogic content knowledge which the teacher possesses. Teachers need to be familiar with the interrelationships of those elements such that they understand why they are responding, mathematically, to particular learners in particular ways (Greeno 1991). What these elements might be has been the focus of a number of studies (Jordan et al. 2007; Gersten, Jordan, and Flojo 2005; Malofeeva et al. 2004; Yang, Li, and Li 2008; Griffin 2004; Desoete and Grégoire 2006). Several core areas seem to be involved (Jordan et al. 2007):

1. Number Knowledge: comparing quantities, such as which of two numbers is larger or smaller.

2. Counting Skills and Principles: knowledge of the count sequence, enumeration of sets, number recognition, and understanding of counting principles.

3. Nonverbal Calculation: performing addition and subtraction transformations with concrete referents.

4. Number Combinations: retrieving from memory 'number facts' as in responding to 'What is 3 and 4 ?' with no concrete referents.

5. Story Problems: solving word problems in which objects are referred to but not visible: 'Jill has two toys. Jim gives her one more toy. How many toys does Jill have now?'

\section{Number Knowledge}

Number Knowledge is fundamental understanding of how numbers are (de)composed. It is a 'central conceptual structure' (Okamoto and Case 1996) which allows people to construct more complex numerical understanding. Early socialisation exposes preschool children to appropriate (albeit preliminary) knowledge of written numerals, of number words, of cardinal set values, and a pointing routine for 'tagging' objects while counting (Case 1996). When the children are around 6-years-of-age these different pieces of knowledge are thought to merge into a mental number line: a tool with which they integrate their experiences of number and any numerical instruction they may receive. The construction of the mental number line is significant because it evidences an understanding that activities involving numbers are not just 'out there' but something that occur inside one's own head and can be under one's own control.

As well as knowledge of addition and subtraction, Number Knowledge is indexed by understanding magnitude comparison: knowing which of two or more numbers is bigger/biggest or smaller/smallest and, relatedly, identifying missing 
numbers in a sequence. Poor performance in magnitude comparison along with poor performance in Counting (see below) partly explains low arithmetic performance (Butterworth and Laurillard 2010; Lyons and Beilock 2011). Proficiency in magnitude comparison is strongly associated with memory for numbers, familiarity with Arabic numerals, and with simple arithmetical performance (Booth and Siegler 2008; Chard et al. 2008; De Smedt, Verschaffel, and Ghesquière 2009; Thompson and Siegler 2010; Holloway and Ansari 2009).

Naming numbers, patterning numbers, identifying missing numbers, and comparing magnitudes all correlate with positive arithmetical learning by the end of the first year of schooling (Clarke and Shinn 2004) and are tasks that teachers can incorporate into learning activities. Promoting such tasks encourages learners to focus on the deep meaning of pattern and structure, and is rewarded in improved numerical attainment (Papic and Mulligan 2007; Mulligan and Mitchelmore 2009).

Knowing that the numerical distance between 16 and 9 is greater than that between 11 and 9 requires automatic recall of the Number Combinations of 16-9 and 11-9. Children need to retrieve readily many (about 100) basic facts before engaging comprehensively with magnitude comparison. Working with an actual, and later a mental, number line habituates the child to positive and negative numbers, to estimation, and to seriation (Schneider et al. 2008). Tasks requiring estimation (Van Den Heuvel-Panhuizen 2003) as distinct from precise computation position learners to translate between alternative quantitative representations, thereby increasing the sophistication and efficiency of their own number knowledge (Siegler and Booth 2004). Playing numerical board games improves understanding of numerical magnitudes, counting, number recognition (Siegler 2010) which are needed for reasoning quantitatively.

\section{Counting Skills and Principles}

Counting is often recognised through the rehearsal of the counting names but is, more precisely, the co-ordination of a countable with a number name. In any given set of items one and only one number word (from a stable list of number words) is assigned to each object in the set. As long as all countables are included (and none is missed) it does not matter in which order they are counted, so long as the list of counting referents is a stable one (though not necessarily conventionally correct) and a distinct referent is used for each countable (no one referent can be used twice in the same count).

Variations in the child's attack on a counting task can be observed, beginning with 'counting-all': counting each collection and then counting the combination of two collections starting from one (that is, $2+5=1,2 \ldots .1,2,3,4,5 \ldots 1,2,3,4,5,6,7$ ). Encouraging those who 'count-all' to 'count-on' - accept one set as a given and count on the number of the second set $(\operatorname{so}, 2+5=(2), 3,4,5,6,7)$ - allows more 
effective counting. But successful 'counting-on' requires the correct coordination of the sets being counted to keep track of what has been, and what is still to be, counted. Even more efficient is determining the larger collection and 'counting-on' the number of times indicated by the smaller set (that is, $2+5=(5), 6,7)$. Being able to 'count-on' rather than rely only on 'count-all' is a significant accomplishment, signalling a grasp of part-whole relations which are critical to quantitative reasoning (Nunes, Bryant, and Watson 2009). Appreciating 'counting-on' as a valid and more efficient way of determining a numerosity reflects the understanding that we can count either non-visible or perceptually dissimilar objects and, by default, evidences the capacity to unitise quantity at least to some extent (Steffe, Thompson, and Richards 1982). However it is a developmental achievement to start counting at a number other than 1 and to use 'counting-on' strategies spontaneously (Resnick 1983; Fuson 1983). Teachers therefore can offer repeated opportunities to practice counting, integrating counting with the other dimensions of Number Sense. Ultimately this allows the emergence of number combination retrieval, not as a rote technical skill but as meaningful insight into the abstract quality of Number (Blöte, Klein, and Beishuizen 2000; Rittle-Johnson, Siegler, and Alibali 2001; Zur and Gelman 2004). Many children start school counting effectively, even if not always efficiently, and can use their counting to solve multiplication and division problems. Teachers, thus, can be aware of children's extant quantitative reasoning and how they enable learners to use it for further learning (Nunes, Bryant, and Watson 2009).

Counting in its fullest sense is epitomised by cardinality (Gelman and Gallistel 1978): the understanding that the set's numerosity is represented by a number word. Understanding the relationship between the numerosity of a set and how the numerosity is derived, is evidenced when children can correctly compare the numerosity of one set with that of another, and when this comparison is based on some method of quantification (Bryant 1997). In other words, children need (and may need help) to realise that counting and comparing are powerfully related ideas. To determine whether a child's counting is only procedural or is actually cardinal, Bermejo and others (LeFevre, Smith-Chant, Fast, Skwarchuk, Sargla, Penner-Wilger, et al. 2006; Muldoon, Lewis, and Francis 2007) identified a neat discrimination task: identifying miscounts. This task requires children to judge whether a particular count has been executed correctly. A tangible proxy is introduced as sometimes making mistakes because of just learning how to count. It is explained that the puppet or stuffed toy is now going to count and that the child is to determine whether the proxy makes a mistake. Different contexts for counting are presented and after each count the 'How many' question is asked. Teachers can use this 'game' as a formative task on an individual and collective basis. Observing a learner judging the validity of another's procedures gives 
teachers insight into the sophistication of learners' understandings: those who themselves count a set correctly have procedural knowledge while those who detect errors in the counting of others have conceptual knowledge of counting (Freeman, Antonucci, and Lewis 2000; LeFevre, Smith-Chant, Fast, Skwarchuk, Sargla, Arnup, et al. 2006).

According to Bermejo and colleagues (Bermejo, Morales, and Garcia de Osuna 2004; Bermejo 1996) cardinality develops through six stages:

1. No understanding of cardinality. Response to the' how many' question is random.

2. Partial count-cardinal reference. Offers a number string as the response but without pointing or making reference to the items of the set.

3. Full count-cardinal reference. Makes reference to the objects of the set, and points with finger to each object while counting. If asked again, "But how many items are there?" they point once more to each of the objects, counting again, but without giving a single number word.

4. The last-word rule. Gives the last counted word as the answer to the 'how many' question but also gives the last word in various situations in which the count is incorrect; for example by counting four countables and, having been instructed to start at 'two', declares there to be 5 objects.

5. A partial cardinal response. Gives the largest number but if the standard order of the sequence is changed, they still pronounce the largest number as the cardinal value.

6. A true cardinality answer. Children answer the cardinality question with the number word that correctly refers to the number of items in the set.

Bermejo believes that children who are at least at level 4 (use the Last-Word Rule) in the hierarchy can rapidly progress to true cardinality by experiencing the cognitive conflict that comes from practice in counting sets starting with different numbers. Further, exposure to number words in all their differing contexts (Fuson and Hall 1983) is positively related to children's grasp of cardinal meaning (Levine et al. 2010). Cardinality is important conceptual and procedural knowledge which is needed in the development of early QL.

\section{Nonverbal Calculation}

Children's earliest abilities in addition and subtraction are based on their experiences of combining and separating sets of objects in the real world (Gelman and Gallistel 1978). Although this is most readily observed in counting tasks, Nonverbal Calculation is classically evidenced in a task in which an initial quantity is displayed to the child, and then screened from view. The child watches as the teacher alters the initial quantity through adding or removing items. Understanding of addition or subtraction is confirmed when the child matches the 
transformation by counting out the appropriate result with countables (Levine, Jordan, and Huttenlocher 1992). Successful Nonverbal Calculation gives insight into the child's quantitative representations without the intervening variables of language (as occurs in Story Problems) and Number Combinations which may have been developed by rote (see below); it is an ability that typically precedes both (Levine, Jordan, and Huttenlocher 1992). Nonverbal Calculation is an important achievement because it marks some understanding of 'counting-on' and 'counting-back' and an appreciation of counting as an abstract activity (Gray, Pitta, and Tall 2000).

\section{Number Combinations}

The retrieval from memory of basic number combinations of single-digit addition and related subtraction has long since been considered desirable. Everyday tasks such as counting change, calculating time and cooking are more straightforward if one knows 'the number facts'. Additionally, their retrieval reduces cognitive overload when such knowledge is needed in more advanced operations. Children who do not master Number Combinations experience considerable difficulty (Baroody, Bajwa, and Eiland 2009; Geary et al. 2007; Jordan and Hanich 2003).

Typically Number Combinations develop in three phases: counting (as discussed above), reasoning from known facts and relations to deduce a new combination, and mastery (retrieving the answer from memory). If children can be encouraged to use their own knowledge through counting and reasoning, there can be an almost seamless morphing into automatic recall which, reflecting a well-integrated network of conceptual and procedural knowledge, equips learners with knowledge with which they can reason quantitatively. On the other hand, Number Combinations drilled at the expense of meaning result in speedy recall in familiar tasks and corresponding difficulty in unfamiliar tasks (Baroody, Bajwa, and Eiland 2009). The point being made is that exposure to counting and reasoning tasks allows learners to use their own strategic knowledge with increasing efficiency such that they themselves discern the value of fluent Number Combinations. This does not detract from the clear expectation that the learners should demonstrate mastery in Number Combinations (Geary et al. 2007; Gersten, Jordan, and Flojo 2005) but, rather, draws attention to the pedagogical importance of focusing on the structure of Number to facilitate this achievement.

\section{Story Problems}

Insofar as it requires the transfer of what has been learned to a new situation, solving Story Problem epitomises QL since the synergistic relationship of conceptual and procedural knowledge is central to the application of quantitative knowledge in everyday life (Blum and Niss 1991; Verschaffel et al. 2010; Doorman et al. 2007). Story Problems are typically short pieces of text which 
identify some quantities, describe a relationship among the quantities, and pose a problem which is to be solved through explicit and exclusive use of the given information (Riley, Greeno, and Heller 1983).

Story problems make varying demands on the problem solver (Verschaffel, Greer, and De Corte 2000). Those who use the strategy of direct translation (Mayer and Hegarty 1996) select the key numbers and perform an arithmetic operation that is most strongly primed by the keywords in the problem (so, the word 'altogether' would trigger an addition operation). Using the direct translation strategy would mean that the problem-solver would not distinguish between birthday cards and Christmas cards in the following shell, 'A shop sells 312 XXXXX cards in December. About how many will it sell altogether in January, February and March?' In contrast, those who use the strategy of problem modelling will construct an understanding of what the problem $i s$, of a plan to solve the problem and finally will execute the plan. Evidence suggests that persons using problem modelling spend more time ensuring they understand what the problem demands, but also have a higher success rate than those who use the more superficial direct translation.

While computation skill (so readily invoked in direct translation) may be a necessary part of numerical problem-solving, it is not sufficient (Vukovic and Siegel 2010; Nunes, Schliemann, and Carraher 1993; Cowan et al. 2011). Learners need repeated and broad practice in attending to situations in which the arithmetic procedures are variable, thereby causing learners to model the problem fully (Fuchs et al. 2004; Fuchs et al. 2006; Fuchs et al. 2008; Schwartz et al. 2011). It is through practice on real and realistic problems that learners develop and enact their growing QL (Enyedy and Mukhopadhyay 2007) rather than on the impoverished diet of problems typically deployed (Verschaffel, Greer, and De Corte 2000; Palm 2008).

Like other dimensions of Number Sense, there is a developmental trajectory in mastering Story Problems (Baroody et al. 2009; Vukovic and Siegel 2010). Modelling may begin with manipulatives or pictorial referents to represent quantities (Lesh, Post, and Behr 1987) through 'seeing' quantities in one's head (Gray, Pitta, and Tall 2000) to principle-based reasoning where repeated opportunity to derive new number knowledge allows learners to construct their own rules and generalisations (Baroody et al. 2009; Baroody, Bajwa, and Eiland 2009; Palm 2008). A child at an early representational stage of modelling with manipulatives may find it difficult to simultaneously consider the relationship (Thompson 1993) indicated in the particular Story Problem's structure (Riley, Greeno, and Heller 1983). 


\section{Concluding Remarks}

This paper has argued that there are interdependent dimensions of knowledge (collectively known as Number Sense) which must be surfaced by teachers to promote the development of QL. For all of these dimensions there is evidence that testifies to their importance and to difficulties for learners if/when underdeveloped. Poorly developed Number Sense impedes the development of QL. Focusing on Number Sense equips teachers to identify/remedy gaps in learning progress.

The considerable evidence which points to why early QL may not be developing as soundly as it might implicates professional development. First is the need to cultivate the pedagogical expertise of professional noticing. In the context of Numeracy, professional noticing includes, iteratively, attending to learners' overt quantitative behaviour; teasing out and interpreting learners' understandings of quantification; and responding on the basis of what has been noticed earlier. The dimensions of Number Sense provide the foundations for pedagogical responses. While the teacher's 'habit of mind' to intervene diagnostically may develop slowly and minimally to begin with, this merely indicates that pedagogical expertise is highly nuanced.

Second is the need to believe that quantitative thinking is both important and complex. Thus analysing, patterning and constructing number are high-priority activities; metacognitive awareness of quantitative behaviour needs to be explicit in classroom talk; and conceiving of real-life, social situations in quantitative terms has to be a routine part of pedagogy. Classroom tasks such as those identified in the sections above are not trivial incidentals and can enable learning.

Third is the need to challenge extant inadequacies about quantification. Impoverished teaching cannot, by default, be legitimised by teachers' dislike, fear, or ignorance of number and quantification.

While it is easier to make recommendations than to design or implement them, it is important to remember that dialogue, reflection, and discussion are central to teacher learning. Generating contexts for this to occur need not be overwhelming. Regardless of whether teaching at early or later stages of school, profound teaching involves learners constructing understandings of quantification. As teachers work together on matters that are situated in practice, they attempt to understand how each deals with specific dimensions of Number Sense. In so doing, they may identify inconsistencies in their collective knowledge and perhaps consult authoritative sources. If they, further, monitor collaborative effort and negotiate future courses of action, they are themselves steering and organising the construction of their corporate knowledge through taking account of different contributions in the context of their own teaching. It is within this critically collaborative context that the review presented here is offered. 


\section{References}

Baroody, A., N. Bajwa, and M. Eiland. 2009. Why can't Johnny remember the basic facts? Developmental Disabilities Research Reviews 15 (1): 69-79. http://dx.doi.org/10.1002/ddrr.45

Baroody, A., M. Lai, X. Li, and A. Baroody. 2009. Preschoolers' understanding of subtraction-related principles. Mathematical Thinking and Learning 11 (1): 41-60. http://dx.doi.org/10.1080/10986060802583956

Behr, M., G. Harel, T. Post, and R. Lesh. 1994. Units of quantity: a conceptual basis common to additive and multiplicative structures. In The Development of Multiplicative Reasoning in the Learning of Mathematics, ed. G. Harel and J. Confrey, 121-176. Albany, NY: State University of New York Press.

Berch, D. Making sense of number sense. Journal of Learning Disabilities 38 (4): 333-339. http://dx.doi.org/10.1177/00222194050380040901

Bermejo, V. 1996. Cardinality development and counting. Developmental Psychology 32 (2): 263-268. http://dx.doi.org/10.1037/0012-1649.32.2.263

- S. Morales, and J. Garcia de Osuna. 2004. Supporting children's development of cardinality understanding. Learning and Instruction 14: 381-398. http://dx.doi.org/10.1016/j.learninstruc.2004.06.010

Biddlecomb, B., and M. Carr. 2011. A longitudinal study of the development of mathematics strategies and underlying counting schemes. International Journal of Science and Mathematics Education 9 (1): 1-24. http://dx.doi.org/10.1007/s10763-010$\underline{9202-y}$

Blöte, A., A. Klein, and M. Beishuizen. 2000. Mental computation and conceptual understanding. Learning and Instruction 10: 221-247. http://dx.doi.org/10.1016/S0959-4752(99)00028-6

Blum, W., and M. Niss. 1991. Applied mathematical problem solving, modelling, applications, and links to other subjects: state, trends and issues in mathematics instruction. Educational Studies in Mathematics 22 (1): 37-68. http://dx.doi.org/10.1007/BF00302716

Booth, J., and R. Siegler. 2008. Numerical magnitude representations influence arithmetic learning. Child Development 79 (4): 1016-1031. http://dx.doi.org/10.1111/j.1467-8624.2008.01173.x

Bryant, P. 1997. Mathematical understanding in the nursery school years. In Learning and Teaching Mathematics, ed. T. Nunes and P. Bryant, 53-67. East Sussex: Psychology Press.

Butler, D., B. Beckingham, and H. Lauscher. 2005. Promoting strategic learning by eighth-grade students struggling in mathematics: a report of three case studies. Learning Disabilities Research and Practice 20 (3): 156-174. http://dx.doi.org/10.1111/j.1540-5826.2005.00130.x

Butterworth, B., and D. Laurillard. 2010. Low numeracy and dyscalculia: identification and intervention. Zentralblatt für Didaktik der Mathematik (ZDM) 42: 527-539. http://dx.doi.org/10.1007/s11858-010-0267-4 
Case, R. 1996. Reconceptualizing the nature of children's conceptual structures and their development in middle childhood. Monographs of the Society for Research in Child Development 61 (1/2): 1-26. http://dx.doi.org/10.2307/1166077

Chard, D., S. Baker, B. Clarke, K. Jungjohann, K. Davis, and K. Smolkowski. 2008. Preventing early mathematics difficulties: the feasibility of a rigorous kindergarten mathematics curriculum. Learning Disability Quarterly 31 (1): 11-20.

Clarke, B., and M. Shinn. 2004. A preliminary investigation into the identification and development of early mathematics curriculum-based measurement. School Psychology Review 33 (2): 234-248.

Clements, D., and J. Samara. 2007. Early Childhood mathematics learning. In Second Handbook on Mathematics Teaching and Learning, ed. F. Lester, 461-555. Charlotte, NC: Information Age.

Cowan, R., C. Donlan, D. Shepherd, R. Cole-Fletcher, M. Saxton, and J. Hurry. 2011. Basic calculation proficiency and mathematics achievement in elementary school children. Journal of Educational Psychology 103 (4): 786-803. http://dx.doi.org/10.1037/a0024556

Davydov, V. 1982. The psychological characteristics of the formation of elementary mathematical operations in children. In Addition and Subtraction: A Cognitive Perspective, ed. T. Carpenter, J. Moser and T. Romberg, 224-238. Hillsdale, N.J.: Lawrence Erlbaum Associates.

De Corte, E. 2010. Historical developments in the understanding of learning. In The Nature of Learning: Using Research to Inspire Practice, ed. H. Dumont, D. Istance and F. Benavides, 35-67. Paris: OECD Publishing.

De Smedt, B., D. Ansari, R. Grabner, M. Hannula, M. Schneider, and L. Verschaffel. 2010. Cognitive neuroscience meets mathematics education. Educational Research Review 5: 97-105. http://dx.doi.org/10.1016/j.edurev.2009.11.001

De Smedt, B., and L. Verschaffel. 2010. Traveling down the road: from cognitive neuroscience to mathematics education ... and back. ZDM 42 (6): 649-654.

— comparison for individual differences in mathematics achievement. Journal of Experimental Child Psychology 103: 469-479. http://dx.doi.org/10.1016/j.jecp.2009.01.010

Desoete, A., and J. Grégoire. 2006. Numerical competence in young children and in children with mathematics learning disabilities. Learning and Individual Differences 16: 351-367. http://dx.doi.org/10.1016/j.lindif.2006.12.006

Doorman, M., P. Drijvers, T. Dekker, M. Van Den Heuvel-Panhuizen, J. De Lange, and M. Wijers. 2007. Problem solving as a challenge for mathematics education in The Netherlands. ZDM 39 (5): 405-418. http://dx.doi.org/10.1007/s11858-007-0043-2

Enyedy, N., and S. Mukhopadhyay. 2007. They don't show nothing I didn't know: Emergent tensions between culturally relevant pedagogy and mathematics pedagogy. Journal of the Learning Sciences 16 (2): 139-174. http://dx.doi.org/10.1080/10508400701193671

Freeman, N., C. Antonucci, and C. Lewis. 2000. Representation of the cardinality principle: Early conception of error in a counterfactual test. Cognition 74:71-89. http://dx.doi.org/10.1016/S0010-0277(99)00064-5 
Fuchs, L., D. Fuchs, D. Compton, S. Powell, P. Seethaler, A. Capizzi, C. Schatschneider, and J. Fletcher. 2006. The cognitive correlates of third-grade skill in arithmetic, algorithmic computation, and arithmetic word problems. Journal of Educational Psychology 98 (1): 29-43. http://dx.doi.org/10.1037/0022-0663.98.1.29

Fuchs, L., D. Fuchs, S. Powell, P. Seethaler, P. Cirino, and J. Fletcher. 2008. Intensive intervention for students with mathematics disabilities: Seven principles of effective practice. Learning Disability Quarterly 31 (2)): 79-92.

Fuchs, L., D. Fuchs, K. Prentice, C. Hamlett, R. Finelli, and S. Courey. 2004. Enhancing mathematical problem solving among third-grade students with schema-based instruction. Journal of Educational Psychology 96 (4): 635-647. http://dx.doi.org/10.1037/0022-0663.96.4.635

Fuson, K. 1983. An analysis of the counting-on solution procedure in addition. In Addition and Subtraction: A Cognitive Perspective, ed. T. Carpenter, J. Moser and T. Romberg, 67-81. Hillsdale, N.J.: Lawrence Erlbaum Associates, 1983.

_., and J. Hall. 1983. The acquisition of early number word meanings: A conceptual analysis and review. In The Development of Mathematical Thinking, ed. H. Ginsburg, 49-107. London: Academic Press.

Geary, D., M. Hoard, J. Byrd-Craven, L. Nugent, and C. Numtee. 2007. Cognitive mechanisms underlying achievement deficits in children with mathematical learning disability. Child Development 78 (4): 1343-1359. http://dx.doi.org/10.1111/j.14678624.2007.01069.x

Gelman, R., and C. Gallistel. 1978. The Child's Understanding of Number. Cambridge Harvard University Press.

Gersten, R., N. Jordan, and J. Flojo. 2005. Early identification and interventions for students with mathematics difficulties. Journal of Learning Disabilities 38 (4): 293304. http://dx.doi.org/10.1177/00222194050380040301

Gravemeijer, K. 2004. Local instruction theories as means of support for teachers in reform mathematics education. Mathematical Thinking and Learning 6 (2): 105128. http://dx.doi.org/10.1207/s15327833mt10602_3

Gray, E., D. Pitta, and D. Tall. 2000. Objects, actions, and images: a perspective on early number development. The Journal of Mathematical Behavior 18 (4): 401-413. http://dx.doi.org/10.1016/S0732-3123(00)00025-0

Greenhalgh, T., G. Robert, P. Bate, O. Kyriakidou, F. Macfarlane, and R. Peacock. 2004. How to spread ideas: a systematic review of the literature on diffusion, dissemination and sustainability of innovations in health service delivery and organisation edited by National Co-ordinating Centre for NHS Service Delivery and Organisation R \& D (NCCSDO). London: BMJ Publications.

Greeno, J. 1991. Number sense as situated knowing in a conceptual domain. Journal for Research in Mathematics Education 22 (3): 170-218. http://dx.doi.org/10.2307/749074

Greer, B., L. Verschaffel, and E. De Corte. 2002. The answer is really 4.5. In Beliefs: A hidden Variable in Mathematics Education?, ed. G. Leder, E. Pehkonen and G. Törner, 271-292. Dordrecht: Kluwer Academic Publishers, 2002.

Griffin, S. 2004. Building number sense with Number Worlds: A mathematics program for young children. Early Childhood Research Quarterly 19 (1): 173-180. http://dx.doi.org/10.1016/j.ecresq.2004.01.012 
Holloway, I., and D. Ansari. 2009. Mapping numerical magnitudes onto symbols: the numerical distance effect and individual differences in children's mathematics achievement. Journal of Experimental Child Psychology 103 (1): 17-29. http://dx.doi.org/10.1016/j.jecp.2008.04.001

Hughes-Hallett, D. 2001. The role of mathematics courses in the development of quantitative literacy Paper read at Quantitative Literacy: Why Numeracy Matters for Schools and Colleges, at National Academy of Sciences in Washington, D.C.

Jordan, N., J. Glutting, and C. Ramineni. 2008. A number sense assessment tool for identifying children at risk for mathematical difficulties. In Mathematical Difficulties, ed. A. Dowker. London: Academic Press, 2008.

Jordan, N., and L. Hanich. 2003. Characteristics of children with moderate mathematics deficiencies: a longitudinal perspective. Learning Disabilities Research and Practice 18 (4): 213-221. http://dx.doi.org/10.1111/1540-5826.00076

Jordan, N., D. Kaplan, M. Locuniak, and C. Ramineni. 2007. Predicting first-grade math achievement from developmental number sense trajectories. Learning Disabilities Research and Practice 22 (1): 36-46. http://dx.doi.org/10.1111/j.15405826.2007.00229.x

Klein, A., and P. Starkey. 1987. The origins and development of numerical cognition: A comparative analysis. In Cognitive Processes in Mathematics, ed. J. Sloboda and D. Rogers, 1-25. Oxford: Clarendon Press.

Kuhn, D., and S. Pearsall. 2001. Developmental origins of scientific thinking. Journal of Cognition and Development 1: 113-129. http://dx.doi.org/10.1207/S15327647JCD0101N_11

Kühne, C. , M. Van Den Heuvel-Panhuizen, and P. Ensor. 2005. Learning and teaching early number: teachers' perceptions. Paper read at 29th Conference of the International Group for the Psychology of Mathematics Education, at Melbourne.

Le Corre, M., G. Van de Walle, E. Brannon, and S. Carey. 2006. Re-visiting the competence/performance debate in the acquisition of the counting principles. Cognitive Psychology 52 ( 2): 130-169. http://dx.doi.org/10.1016/j.cogpsych.2005.07.002

LeFevre, J., B. Smith-Chant, L. Fast, S. Skwarchuk, E. Sargla, J. Arnup, M. PennerWilger, J. Bisanz, and D. Kamawar. 2006. What counts as knowing? the development of conceptual and procedural knowledge of counting from kindergarten through Grade 2. Journal of Experimental Child Psychology 93: 285-303. http://dx.doi.org/10.1016/j.jecp.2005.11.002

Lembke, E., and A. Foegen. 2009. Identifying early numeracy indicators for kindergarten and first-grade students. Learning Disabilities Research and Practice 24 (1): 12-20. http://dx.doi.org/10.1111/j.1540-5826.2008.01273.x

Lesh, R., T. Post, and M. Behr. 1987. Representations and translations among representations in mathematics learning and problem solving. In Problems of Representation in the Teaching and Learning of Mathematics, ed. C. Janvier, 33-40. Hillsdale, N.J.: Lawrence Erlbaum Associates.

Levenson, E., P. Tsamir, and D. Tirosh. 2010. Mathematically based and practically based explanations in the elementary school: teachers' preferences. Journal of Mathematics Teacher Education 13 (4): 345-369. http://dx.doi.org/10.1007/s10857$\underline{010-9142-\mathrm{z}}$ 
Levine, S., N. Jordan, and J. Huttenlocher. 1992. Development of calculation abilities in young children. Journal of Experimental Child Psychology 53 (1): 72-103. http://dx.doi.org/10.1016/S0022-0965(05)80005-0

Levine, S., L. Suriyakham, M. Rowe, J. Huttenlocher, and E. Gunderson.2010. What counts in the development of young children's number knowledge? Developmental Psychology 46 (5): 1309-1319. http://dx.doi.org/10.1037/a0019671

Lyons, I., and S. Beilock. 2011. Numerical ordering ability mediates the relation between number-sense and arithmetic competence. Cognition 121: 256-261. http://dx.doi.org/10.1016/j.cognition.2011.07.009

Madison, B. 2001. Quantitative literacy: Everybody's orphan. Focus 21 (6): 10-11.

- and L. Steen. 2008. Evolution of numeracy and the national numeracy network. Numeracy 1 1): Article 2. http://dx.doi.org/10.5038/1936-4660.1.1.2

Malofeeva, E., J. Day, X. Saco, L. Young, and D. Ciancio. 2004. Construction and evaluation of a number sense test with Head Start Children. Journal of Educational Psychology 96 (4): 648-659. http://dx.doi.org/10.1037/0022-0663.96.4.648

Marzano, R., and J. Kendall. 2007. The New Taxonomy of Educational Objectives. Thousand Oaks, CA: Corwin Press.

Mayer, R., and M. Hegarty. 1996. The process of understanding mathematical problems. In The Nature of Mathematical Thinking, ed. R. Sternberg and T. Ben-Zeev, 29-53. Mahwah, NJ: Lawrence Erlbaum Associates.

Mazzocco, M., and R. Thompson. 2005. Kindergarten predictors of math learning disability. Learning Disabilities Research and Practice 20 (3): 142-155. http://dx.doi.org/10.1111/j.1540-5826.2005.00129.x

McIntosh, A., B. Reys, and R. Reys. 1992. A proposed framework for examining basic number sense. For the Learning of Mathematics 12 (3): 2-8.

Muldoon, K., C. Lewis, and B. Francis (2007). Using cardinality to compare quantities: The role of social-cognitive conflict in early numeracy. Developmental Science 10 (5): 694-711. http://dx.doi.org/10.1111/j.1467-7687.2007.00618.x

Mulligan, J., and M. Mitchelmore. 2009. Awareness of pattern and structure in early mathematical development. Mathematics Education Research Journal 21 (2): 3349. http://dx.doi.org/10.1007/BF03217544

Murray, F. 2007. The licensure of teachers for quantitative literacy: Who should be entitled to teach QL? Paper read at Calculation vs. Context: quantitative literacy and its implications for teacher education, at Wisconsin.

Nathan, M. , B. Eilam, and S. Kim. 2007. To disagree, we must also agree: How intersubjectivity structures and perpetuates discourse in a mathematics classroom." Journal of the Learning Sciences 16 (4): 523-563. http://dx.doi.org/10.1080/10508400701525238

Newby, P. 2010. Research Methods for Education. Harlow, England: Longman.

Newman, M., and K. Dickson. 2012. A systematic review. In Research Methods and Methodologies in Education, ed. J. Arthur, M. Waring, R. Coe and L. Hedges, 141146. London: Sage Publications Ltd.

Nunes, T., and P. Bryant. "Understanding whole numbers." In Key Understandings in Mathematics Learning, edited by T. Nunes, P. Bryant and A. Watson, 38-75. London: Nuffield Foundation, 2009. 
Nunes, T., P. Bryant, and A. Watson. 2009. Key Understandings in Mathematics Learning. London: Nuffield Foundation.

Nunes, T., A. Schliemann, and D. Carraher. 1993. Street Mathematics and School Mathematics. Cambridge, UK: Cambridge University Press.

Obersteiner, A., T. Dresler, K. Reiss, A. Vogel, R. Pekrun, and A. Fallgatter. 2010. Bringing brain imaging to the school to assess arithmetic problem solving: chances and limitations in combining educational and neuroscientific research. ZDM 42 (6): 541-554. http://dx.doi.org/10.1007/s11858-010-0256-7

Okamoto, Y., and R. Case. 1996. Exploring the microstructure of children's central conceptual structures in the domain of number. Monographs of the Society for Research in Child Development 61 (1/2): 27-58.

Olive, J., and G. Çağlayan. 2008. Learners' difficulties with quantitative units in algebraic word problems and the teacher's interpretation of those difficulties. International Journal of Science and Mathematics Education 6 (2): 269-292. http://dx.doi.org/10.1007/s10763-007-9107-6

Palm, T. 2008. Impact of authenticity on sense making in word problem solving. Educational Studies in Mathematics 67 (1): 37-58. http://dx.doi.org/10.1007/s10649$\underline{007-9083-3}$

Palys, T. 2008. Purposive sampling. In The Sage Encyclopedia of Qualitative Research Methods, ed. L. Given, 697-698. Thousand Oaks, CA: Sage.

Papic, M., and J. Mulligan. 2007. The Growth of early mathematical patterning: an intervention study. In Mathematics: Essential research, essential practice (Proceedings of the 30th annual conference of the Mathematics Education Research Group of Australasia), ed. J. Watson and K. Beswick, 591-600. Adelaide: MERGA, 2007.

Pawson, R., T. Greenhalgh, G. Harvey, and K. Walshe. 2004. Realist synthesis: An introduction. In ESRC Research Methods Programme University of Manchester.

Piazza, Manuela. 2010. Neurocognitive start-up tools for symbolic number representations. Trends in Cognitive Sciences 14 (12): 542-551. http://dx.doi.org/10.1016/j.tics.2010.09.008

Resnick, L. 1983. A developmental theory of number understanding. In The Development of Mathematical Thinking, ed. H. Ginsburg, 109-151. London: Academic Press.

Riley, M., J. Greeno, and J. Heller. 1983. Development of children's problem-solving ability in arithmetic. In The Development of Mathematical Thinking, ed. $\mathrm{H}$. Ginsburg, 153-196. London: Academic Press.

Rittle-Johnson, B., S. Siegler, and M. Alibali. 2001. Developing conceptual understanding and procedural skill in mathematics: An iterative process. Journal of Educational Psychology 93 (2): 346-362. http://dx.doi.org/10.1037/0022-0663.93.2.346

Sarama, J., and D. Clements. 2004. Building blocks for early childhood mathematics. Early Childhood Research Quarterly 19 (1): 181-189. http://dx.doi.org/10.1016/j.ecresq.2004.01.014

- 2009. Early childhood mathematics education research: Learning trajectories for young children. New York Routledge. 
Schneider, M., A. Heine, V. Thaler, J. Torbeyns, B. De Smedt, L. Verschaffel, A. Jacobs, and Sterna. E. 2008. A validation of eye movements as a measure of elementary school children's developing number sense. Cognitive Development 23: 409-422. http://dx.doi.org/10.1016/j.cogdev.2008.07.002

Schwartz, D., C. Chase, M. Oppezzo, and D. Chin. 2011. Practicing versus inventing with contrasting cases: The effects of telling first on learning and transfer. Journal of Educational Psychology 103 (4): 759-775. http://dx.doi.org/10.1037/a0025140

Seymour, J., and R. Lehrer. 2006. Tracing the evolution of pedagogical content knowledge as the development of interanimated discourses. Journal of the Learning Sciences 15 (4): 549-582. http://dx.doi.org/10.1207/s15327809jls1504_5

Sfard, A. 2007. When the rules of discourse change, but nobody tells you: Making sense of mathematics learning from a commognitive standpoint. Journal of the Learning Sciences, 16, no. 4(2007): 565-613.

Siegler, R. 2010. Playing numerical board games improves number sense in children from low-income backgrounds. British Journal of Educational Psychology no. Monograph Series II 7: 15-29.

— and J. Booth. 2004. Development of numerical estimation in young children. Child Development 75 (2): 428-444. http://dx.doi.org/10.1111/j.1467-8624.2004.00684.x

Steffe, L., P. Thompson, and J. Richards. 1982. Children's counting in problem solving. In Addition and Subtraction: a cognitive perspective, ed. T. Carpenter, J. Moser and T. Romberg, 83-97. Hillsdale, N.J.: Lawrence Erlbaum Associates.

Thompson, C., and R. Siegler. 2010. Linear numerical-magnitude representations aid children's memory for numbers. Psychological Science 21 (9): 1274-1281. http://dx.doi.org/10.1177/0956797610378309

Thompson, P. 1993, Quantitative reasoning, complexity and additive structures. Educational Studies in Mathematics 25: 165-208. http://dx.doi.org/10.1007/BF01273861

Throndsen, I. 2011. Self-regulated learning of basic arithmetic skills: A longitudinal study. British Journal of Educational Psychology 81 (4): 558-578. http://dx.doi.org/10.1348/2044-8279.002008

Van Den Heuvel-Panhuizen, M. 2003. Guides for didactical decision making in primary school mathematics education: the focus on the content domain of estimation. . Paper read at Opening Conference of the Norwegian Center forMathematics Education, 18-19 November, at Trondheim, Norway.

Verschaffel, L., B. Greer, and E. De Corte. 2000. Making sense of word problems, ed. B. Creemers, D. Reynolds and S. Stringfield, CONTEXTS OF LEARNING Classrooms, Schools and Society. Lisse, The Netherlands: Swets \& Zeitlinger.

Verschaffel, L., W. Van Dooren, B. Greer, and S. Mukhopadhyay. 2010. Reconceptualising word problems as exercises in mathematical modelling. Journal für Mathematik-Didaktik 31 (1): 9-29. http://dx.doi.org/10.1007/s13138-010-0007-x

Vukovic, R., and L. Siegel. 2010. Academic and cognitive characteristics of persistent mathematics difficulty from first through fourth grade. Learning Disabilities Research and Practice 25 (1): 25-38. http://dx.doi.org/10.1111/j.1540-5826.2009.00298.x 
Yackel, E., D. Underwood, and N. Elias. 2007. Mathematical tasks designed to foster a reconceptualized view of early arithmetic. Journal of Mathematics Teacher Education 10 (4): 351-367. http://dx.doi.org/10.1007/s10857-007-9044-x

Yang, D., M. Li, and W. Li. 2008. Development of a computerized Number Sense Scale for 3rd graders: Reliability and validity analysis." International Electronic Journal of Mathematics Education 3 (2): 110-124.

Zur, O., and R. Gelman. 2004. Young children can add and subtract by predicting and checking. Early Childhood Research Quarterly 19 (1): 121-137.

http://dx.doi.org/10.1016/j.ecresq.2004.01.003 